\title{
Positive and negative affect during a pandemic: Mediating role of emotional regulation strategies
}

\author{
Ahmet Kara ${ }^{1}$ and Ayşe Gök ${ }^{2}$ \\ ${ }^{1}$ Department of Psychological Counselling and Guidance, Eskisehir Osmangazi University, Turkey (ORCID: 0000-0002-4573-5022) \\ ${ }^{2}$ Department of Psychological Counselling and Guidance, Niğde Ömer Halisdemir University, Turkey (ORCID: 0000-0001-6706-8251)
}

\begin{abstract}
The purpose of the current study is to determine the mediator role of emotional regulation strategies in the relationship between positive affect and negative affect experienced by individuals during the COVID-19 pandemic. A total of 436 individuals witnessing and experiencing the process of the COVID-19 pandemic in Turkey participated in the current study and $310(71.1 \%)$ of the participants are females and $126(28.9 \%)$ are males. The data of the current study were collected by using the Positive - Negative Affect Scale and Emotional Regulation Questionnaire. The path analysis technique was used in the analysis of the data. In order to test the significance of indirect effects, bootstrapping analysis was used by generating 1000 samples. According to the findings of the study, one unit increase in negative affect decreases individuals' use of emotional regulation strategies by $0.13(t=-.2 .829 ; p<.01)$. On the other hand, one unit increase in emotional regulation strategies increases individuals' positive affect by $0.43(t=9.848 ; p<.01)$. In addition, the full mediator role of emotional regulation strategies in the relationship between negative affect and positive affect has been proven. It is thought that the findings obtained as a result of the research can be a guide for mental health professionals and future research.
\end{abstract}

Keywords: COVID-19; Positive affect; Negative affect; Emotional regulation strategies

Article History: Submitted 26 August 2020; Revised 2 November 2020; Published online 7 November 2020

\section{Introduction}

Humans are social and emotional beings. As investigating the basic functions of education in raising people we come across three basic functions. The first of these is to raise human as an individual, the other is raise human as a social being, and last one is raise human as a professional (Yeşilyaprak, 2000). Since emotions has a multicomponent structure consisting of experiential, behavioural, and physiological dimensions, they have a vital importantance of raising people as a social being in education process (Gross, 2013). Through emotions, people not only give meaning to their experiences, but also give meaning to life by organizing self's and the others whom they interact (Duy \& Yild1z, 2014). In addition emotion regulation is an important concept that enable people maintain healthy relationships with their environment by managing their emotional states. (Gross, 2013). Based on these, the concepts of emotions and emotion regulation play an important role especially in the context of raising people, which is the social dimension of education.

Address of Corresponding Author

Ahmet Kara, PhD, Eskisehir Osmangazi University Faculty of Education Meşelik Campus, 26480, Eskisehir, Turkey.

$\triangle$ ahmetkara9126@gmail.com

How to cite: Kara, A. \& Gök, A. (2020). Positive and negative affect during a pandemic: Mediating role of emotional regulation strategies. Journal of Pedagogical Research, 4(4), 484-497. 
On January 13, 2020, a virus epidemic defined as the New Coronavirus Disease (COVID-19) led to a global health crisis. COVID-19 virus, which first manifested itself with respiratory symptoms in late December in Wuhan Province of China, spread from person to person and thus spread to other provinces of the People's Republic of China and then to other countries of the world (Dong \& Bouey, 2020; World Health Organization [WHO], 2020). During this epidemic, individuals have had to struggle with the psychological, sociological and economic consequences as well as the biological effects of the virus.

The uncertainties and limitations brought about by infectious disease outbreaks are one of the most difficult situations to cope with psychologically. Having to be prepared for an unknown situation poses a threat to individuals both physically and mentally. Since a clear time limit for the end of infectious disease outbreaks cannot be predicted, this leaves individuals with a sense of constant risk (Van Bavel et al., 2020). As such, it may be inevitable for individuals to develop emotional reactions regarding the process. One of the most prominent emotional responses in infectious disease outbreaks is fear, and individuals resort to a range of defence systems to cope with such life threats (Le Doux, 2012). People often need to understand the messages given by emotions about the functioning of life. Unpleasant feelings indicate that something is wrong and attention should be focused on this issue. Sometimes, just expressing these feelings can help improve the situation. Nevertheless, it is seen as a more effective way to realize the meaning of the messages given by one's own emotional reactions and to act in this direction (Greenberg, 2002).

Individuals have both basic emotions and some complex emotions. While happiness, surprise, disgust, sadness, anger, humiliation, and fear are basic emotions, emotions such as love, enthusiasm, jealousy and guilt are complex emotions. While basic emotions tend to act, this is not the case with complex emotions. All emotions are different and each has a separate function. For example, positive emotions reflect the level of commitment to life, individuality and awareness (Spindler et al., 2009). Sometimes emotions can be harmful when they are in an inappropriate intensity, duration or frequency for some situations (Gross \& Jazaieri, 2014). There are many unhelpful emotions such as anger that causes the person to harm himself/herself or others and anxiety that disrupts the functioning of life. These are examples of unhelpful emotions that have given rise to the concept of emotional regulation. Emotional regulation is generally defined as the effort to regulate negative emotions in order to reduce the experiential and behavioural aspects of anger, sadness, and anxiety (Gross, 2013). However, in recent years, it has been understood that emotion regulation is not only limited to reducing negative emotions (McRae \& Gross, 2020). This concept also includes the efforts of individuals to regulate their positive emotions by focusing on their feelings such as love, interest and joy (Quoidbach et al., 2010). Reducing negative emotions is accepted as the most common emotional regulation strategy, followed by increasing positive emotions. Emotional regulation strategies that used by individuals can take surprising and varied forms such as focusing on breathing, going for a run, drinking alcohol, reading a book, quitting job, and biting lips. The important thing here is to find ways to organize the numerous strategies that individuals use to regulate their emotions, and then assess whether different strategies are associated with different outcomes (Ford \& Gross, 2018). There are different ways to deal with negative emotions. For example, individuals may suppress the behavioural symptoms that their emotions will reveal, or rethink and try to restructure the situation that reveals the emotion through cognitive reassessment (Gross \& Jazaieri, 2014).

Recent studies have revealed that individuals' strategies for regulating their negative emotions are different. It has been found that the strategies used by individuals to regulate negative emotions are associated with various forms of psychopathology (Aldao et al., 2010; Ehring et al., 2010; Gruber et al., 2012; Sheppes et al., 2015). Problems in emotional regulation can provide predictive power to understand the causes and consequences of emotional disturbances (Berenbaum et al., 2003). People with a history of depression were found to use more suppression and less cognitive reassessment strategies when exposed to a section of a sad film than those who have never had depression (Ehring et al., 2010). Emotional regulation strategies emerge when 
individuals activate their goals (implicit or explicit) related to emotion generation processes. Emotional regulation can be internal/personal (regulating one's own emotions) or external/interpersonal (regulating someone else's emotions), depending on the situation. Emotional regulation strategies in general express what an individual wants to accomplish in relation to certain emotions (Gross, 2013).

\subsection{Relationship between Positive Emotions and Emotional Regulation Strategies}

It is obvious that positive emotions such as excitement, joy, enthusiasm and gratitude give individuals more acceptable and pleasant experiences than negative emotions such as anger, sadness, fear and anxiety (Pressman \& Cohen, 2005). Positive emotions can provide a relaxing effect on individuals' mind by reducing focus on negative emotions. But this effect doesn't mean that positive emotions are just a pleasant distraction. Positive emotions reflect the level of commitment to life and sense of individuality and awareness (Spindler et al., 2009). The balance of positive and negative emotions of individuals is an important step in achieving optimal well-being (Affleck \& Tennen, 1996; Folkman \& Moskowitz, 2000; Fredrickson, 2001). In terms of protecting individuals' mental health and improving existing mental disorders (Yosefi, 2015), realizing positive emotions and using them effectively can be beneficial. This shows the effect of positive emotions on achieving effective emotional regulation (Tugade \& Fredrickson, 2004). It is known that positive emotions expand cognition and increase attention. Cognitively oriented regulation strategies such as reappraisal and adaptive self-reflection are effective in regulating emotions and require a range of cognitive resources. An example of this is when positive emotions occur as a result of a stressful situation help regulate emotions by encouraging cognitive reappraisal and adaptive self-reflection (Folkman \& Moskowitz, 2000; Major, 2013). In a study on the effect of positive emotions on emotion regulation, it was found that individuals who were able to experience gratitude, interest, love and other positive emotions in the midst of the emotional turmoil caused by the terrorist attacks of September 11 showed less depressive symptoms than others (Fredrickson et al., 2003). In conclusion, based on the findings and explanations of the research described above, emotion regulation strategies are considered as an important variable that predicts positive affect in the current study.

\subsection{Relationship between Negative Emotions and Emotional Regulation Strategies}

Negative emotions are also one of the psychological factors that affect the mental health of individuals. Negative emotions are generally accompanied by unpleasant situations such as unhappiness, discontent and unpleasantness (Ghorbani et al., 2020; Spindler et al., 2009). In the literature, there are some research results showing that negative emotions such as anger, hate, guilt and fear are associated with many mental disorders. In the review by McLean and Foa (2017), the relationships between post-traumatic stress disorder, negative emotions, and emotional regulation strategies were investigated. It has been observed that there is a significant relationship between post-traumatic stress disorder and negative emotions such as shame, guilt, anger and disgust and the problems in effective regulation of these emotions. It has been found that such negative emotions and difficulties with emotional regulation strategies are also associated with the severity of post-traumatic stress disorder resulting from various types of trauma. In another study (Heinzen et al., 2011), the relationship between the psychopathic characteristics of 104 young offenders, the degree of their self-reported emotional problems and emotional regulation strategies was investigated. It was concluded that there is a positive and significant relationship between the participants' total psychopathy scores and incompatible emotional regulation strategies. Although psychopathic characteristics are associated with negative emotions such as high levels of anger, anxiety, and sadness (Danziger et al., 2009; Garofalo et al., 2020), no significant relationship was found between total psychopathy scores and emotional symptoms. Recent research findings provide evidence that mood disorders resulting from negative emotions are related to problems with emotional regulation strategies (Casey et al., 2013; Garofalo et al., 2020; Kosson et al., 2018; Vitale et al., 2018). In conclusion, based on the research findings and theoretical explanations 
mentioned above, negative affect is accepted as an important variable that predicts emotional regulation strategies in the current study.

\subsection{The Mediator Role of Emotional Regulation Strategies in the Relationship between Negative Affect and Positive Affect}

In the process of emotional regulation, systems such as attention, information and physiological reactions that give rise to emotions can direct the strategies to be utilized (Koole, 2009). In general, all kinds of stimulant emotion that can create a change in the mood of individuals can affect emotional regulation strategies. As such, many different emotional regulation strategies may be needed when managing emotional life (Koole et al., 2011). In a study in which a cognitive load was a stimulant, it was found that mental control of mood can have ironic effects when the mind is preoccupied with other things (Wegner et al., 1993). While the participants who tried to regulate emotions without having a cognitive load were successful, those who tried to regulate their emotions while keeping a nine-digit number in their memory could not achieve sufficient success in this regard. The participants having a cognitive load also passed into a mood opposite of what they intended to create. This situation can be regarded as an example showing that individuals' emotional regulation strategies may sometimes fail, and they can display unwanted emotions no matter how much they try to avoid them (Koole, 2009). In the study conducted by Chiu et al. (2020), the relationship between anxiety and depressive symptoms of university students and their ability to regulate negative emotions and maintain positive emotions was investigated. As a result of the study, it was found that participants who used strategies to regulate negative emotions less had higher levels of depressive symptoms than those who were more successful in using these strategies. It was observed that the participants with higher levels of depressive symptoms tended to exhibit positive and negative emotions as two separate poles. This indicates that a decrease in negative emotions is equivalent to an increase in positive emotions. In addition, according to Koole (2009), individuals try to redirect the normal flow of their emotions in the process of emotional regulation. If individuals can reasonably handle short or long-term goals with emotion regulation strategies, they can be successful in life (Gross \& Jazaieri, 2014). In the process of emotional regulation, positive and negative emotions can be increased, decreased or maintained (Gross, 1999). In conclusion, based on the research findings and theoretical explanations mentioned above, it is assumed that emotion regulation strategies may have a mediator effect between negative affect and positive affect.

Emotions are related to many of our basic needs and also a communication system that allows us to express our intentions (Ekman \& Friesen, 2003; Kanade et al., 2000). Emotions are thought to be an evolved and innate adaptive system to allow humans to survive and thrive. Emotions are associated with many basic needs of individuals (Frijda, 1986). Emotions provide rapid stimulation in important situations that may threaten the health of the person. The knowledge of what is good and what is bad for a person can be obtained through emotions by evaluating whether the needs are met or not. It is also their emotions that prepare people to act in order to meet their needs (Greenberg, 2002; Le Doux, 1996).

In addition, emotions are the most important elements giving direction to individuals. In crisis situations that affect the majority of the society such as war, natural disaster and epidemic, positive emotions has vital importance to protect individuals' mental health and increase their well-being because individuals who experience positive emotions have a high level of commitment to life (Spindler et al., 2009). It was also found that these individuals show fewer depressive symptoms during a crisis period (Fredrickson et al., 2003). Finally, it is stated that the awareness of these positive emotions and their effective management contribute to the improvement of mental disorders of individuals and to protect their mental health (Yosefi, 2015). In the current COVID-19 pandemic, individuals need to include positive emotions in their lives in order to experience such positive spiritual developments. In order to meet this need, first of all, the factors affecting the positive affect processes of individuals who experience the process of COVID-19 epidemic should 
be revealed. In this regard, the current study is believed to make important contributions to the literature because it aims to determine the mediator role of emotional regulation strategies in the relationship between positive affect and negative affect of the individuals witnessing and experiencing the process of COVID-19 pandemic. To this end, the hypothetical model presented in Figure 1 and hypotheses were constructed.

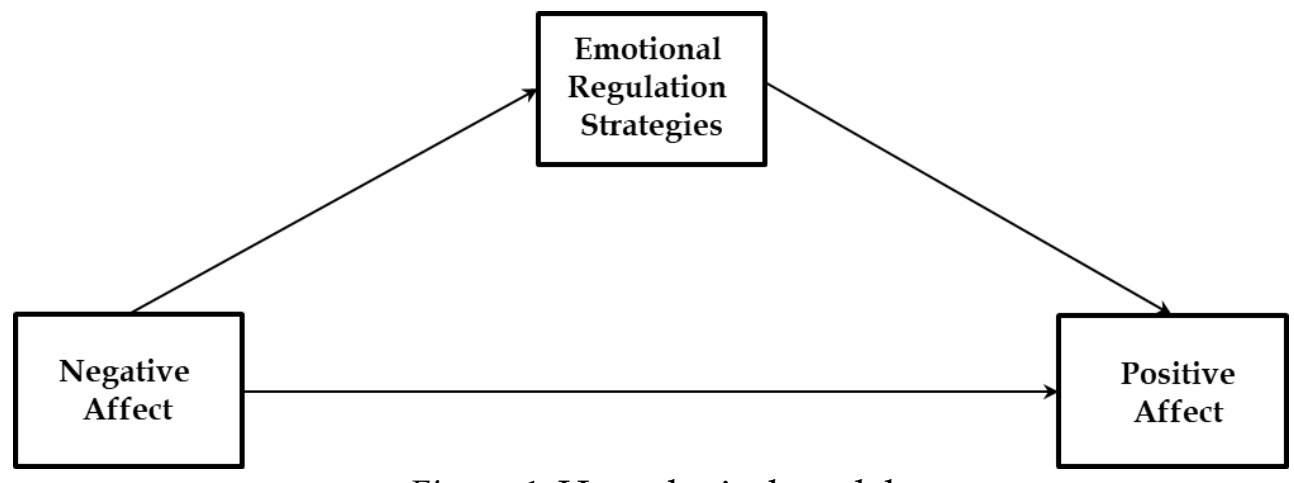

Figure 1. Hypothetical model

Hypothesis 1 . Negative affect significantly and negatively predicts emotional regulation strategies. Hypothesis 2. Negative affect significantly and positively predicts positive affect.

Hypothesis 3. Emotional regulation strategies significantly and positively predict positive affect. Hypothesis 4. Emotional regulation strategies have a mediator role in the relationship between negative affect and positive affect.

\section{Method}

\subsection{Research Model}

This research is designed in a causal pattern. Causal pattern is used when cause and effect relationships are explained between variables (Neuman, 2007). In this study, while the cause variables are negative emotions and emotion regulation strategies; the outcome variable is positive emotions.

\subsection{Study Group}

The data in the current study were collected with an online questionnaire in a period when the COVID-19 pandemic was intensely felt and the number of cases was rapidly increasing in Turkey. A total of 436 individuals witnessing and experiencing the process of the COVID-19 pandemic in Turkey participated in the current study on a volunteer basis and $310(71.1 \%)$ of the participants are females and $126(\% 28.9)$ are males. While selecting these participants, one of the purposeful sampling methods, an appropriate sampling technique was used (Fraenkel \& Wallen, 1993).

\subsection{Measures}

\subsubsection{Positive - Negative Affect Scale (PNAS)}

PNAS was developed by Watson et al. (1988). Adaptation of PNAS to Turkish and its validity and reliability analyzes were conducted by Gençöz (2000). There are a total of 20 items in PNAS. In 10 of these items, there are positive affect statements while in the other 10 items, there are negative affect statements. In the current study, positive affect and negative affect were considered as variables observed separately. In the reliability study of PNAS, exploratory factor analysis was used. As a result of the exploratory factor analysis, the total variance explained in PNAS was found to be $44 \%$ (Gençöz, 2000). In the reliability study of PNAS, the internal consistency coefficient was calculated. The internal consistency coefficient was found to be .88 for the dimension of positive affect and .87 for the dimension of negative affect (Watson et al., 1988). 
In the current study, reliability analysis was conducted on its study group by means of the internal consistency coefficient method. As a result of the reliability analysis, the internal consistency coefficient was found to be .78 for the dimension of positive affect, .88 for the dimension of positive affect and .79 for the whole scale.

\subsubsection{Emotional Regulation Questionnaire (ERQ)}

ERQ was developed by Gross \& John (2003). It was adapted to Turkish by Yurtsever (2004). ERQ consists of 10 items. It has got two dimensions. These dimensions are cognitive reappraisal and suppression. As a result of the reliability analysis conducted by Yurtsever (2004), internal consistency coefficient was found to be .88 for the dimension of cognitive reappraisal and .82 for the dimension of suppression.

In the current study, reliability analysis was conducted on its study group by means of the internal consistency coefficient method. As a result of the reliability analysis, the internal consistency coefficient was found to be .86 for the dimension of cognitive appraisal and .66 for the dimension of suppression and .76 for the whole scale. In the current study, the construct validity of ERQ was examined with first level confirmatory factor analysis. As a result of the first level confirmatory factor analysis, it was concluded that ERQ has an acceptable fit with the data $\left(\mathrm{X}^{2}=124.192 ; \mathrm{df}=34 ; \mathrm{p}=.00 ; \mathrm{X} 2 / \mathrm{sd}=3.65 ; \mathrm{GFI}=.95 ; \mathrm{CFI}=.94 ; \mathrm{NFI}=.92 ; \mathrm{AGFI}=.91 ; \mathrm{RMSEA}=.07\right.$ ( $90 \%$ confidence interval for RMSEA $=.064-.093)$.

\subsection{Data Analysis}

First, preliminary analyses were conducted. In this context, normality, autocorrelation, multicollinearity, descriptive statistics and bivariate correlation analyses were performed. After the preliminary analyses, the path analysis technique was used to reveal the cause-effect relationship between the observed variables. In testing the cause-effect relationship in the path analysis technique, the significance of the path coefficients between the observed variables and whether the goodness of fit indexes were in agreement with the data were examined (Kline, 2015). The goodness of fit indices used in the current study were determined as $\chi 2, \chi 2 / s d$, GFI, CFI, NFI, AGFI and RMSEA. In the interpretation of these goodness of fit indices, the fit criteria suggested by Schermelleh-Engel et al. (2003) were taken into account (see Table 4).

Mediation test was also conducted in the current study. At this point, the stages of mediation testing suggested by Baron and Kenny (1986) were taken into account. Finally, bootstrapping analysis was used to test the significance of indirect effects. In the bootstrapping analysis, 1000 samples were generated and lower-upper limit confidence intervals and bootstrap coefficient were created (Shrout \& Bolger, 2002). According to Hayes (2017), if lower-upper limit confidence intervals do not cover zero, it can be interpreted that their indirect effects are significant.

\section{Results}

\subsection{Preliminary Analysis}

Firstly, the assumptions of normality, autocorrelation and multicollinearity of variables were examined. In addition, descriptive statistics and bivariate correlation analysis were performed. For the assumption of normality, skewness and kurtosis values were examined. In the current study, the skewness values of the variables were found to be varying between -.32 and .13 while the kurtosis values were found to be varying between -.72 and .32 . These values are within the limits of normality according to the normality criteria proposed by Tabachnick and Fidell (2019). Moreover, the autocorrelation assumption was tested with the Durbin-Watson test. In the current study, the Durbin-Watson value was found to be 1.82 . This value shows that there is no autocorrelation problem in the current study (Field, 2009). Finally, the multicollineariy assumption was evaluated with VIF (variance inflation factor) and tolerance values. In the current study, the VIF value was found to be 1.01 while the tolerance value was found to be .98. Evaluated in terms of VIF and tolerance values specified by Kline (2015), it indicates that there is no 
multicollinearity problem in the current study. Table 1 shows means, standard deviations, skewness, kurtosis and bivariate correlation values.

Table 1.

Means, standard deviations, skewness, kurtosis and bivariate correlations

\begin{tabular}{lrrr}
\hline Variable & $\mathbf{1}$ & $\mathbf{2}$ & $\mathbf{3}$ \\
\hline (1) Negative Affect & 1 & & \\
(2) Emotional Regulation Strategies & $-.13^{* *}$ & 1 & \\
(3) Positive Affect & $-.12^{*}$ & $.42^{* *}$ & 1 \\
\hline M & 19.82 & 28.17 & 13.40 \\
SD & 5.71 & 6.28 & 3.61 \\
Skewness & -.21 & -.32 & .13 \\
Kurtosis & -.72 & .32 & -.15 \\
\hline
\end{tabular}

Note. ${ }^{* *} \mathrm{p}<.01 ;{ }^{*} \mathrm{p}<.05$

\subsection{Path Analysis Results of the Hypothetical Model}

The path analysis technique was used to reveal the relationships between the observed variables of positive affect, negative affect and emotional regulation strategies. As a result of the path analysis, the standardized path coefficients of the hypothetical model shown in Figure 2 were obtained and the path analysis results of the hypothetical model are given in Table 2.

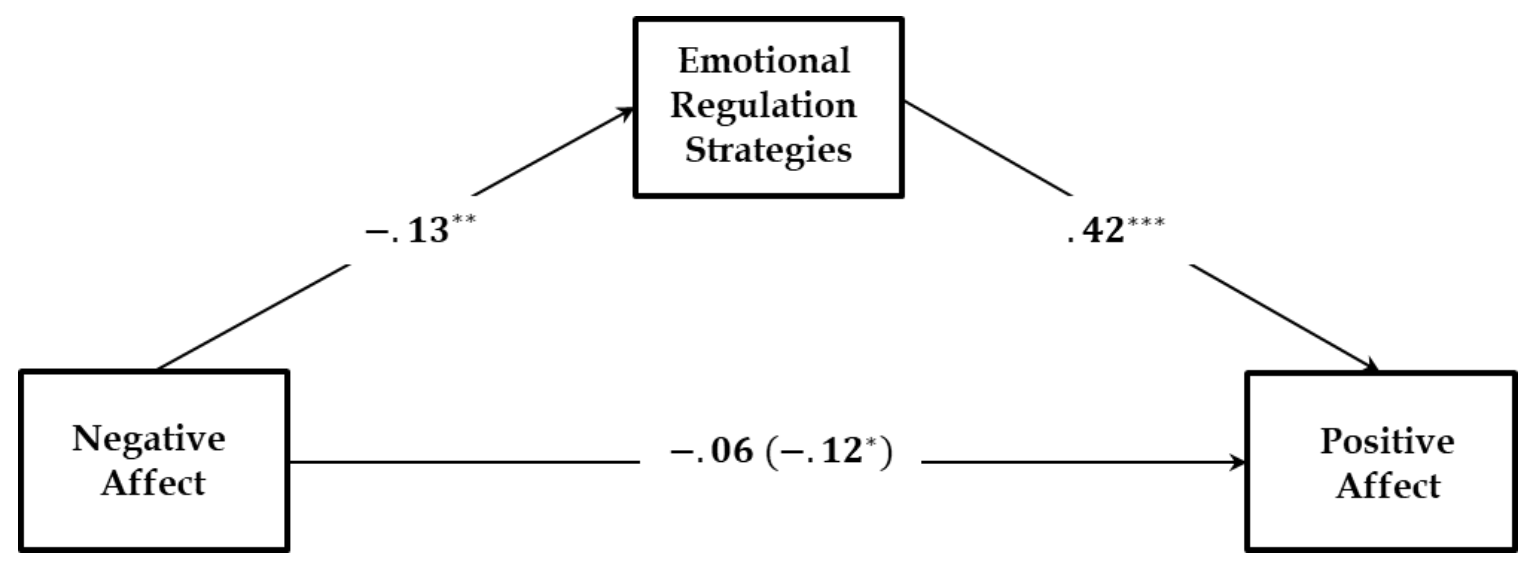

Figure 2. Standardized path coefficients of the hypothetical model

$$
\left({ }^{* * *} \mathrm{p}<.001 ;{ }^{* *} \mathrm{p}<.01 ;{ }^{*} \mathrm{p}<.05\right)
$$

Table 2.

Path Analysis Results of the Hypothetical Model

\begin{tabular}{lllcrcc}
\hline Dependent variable & & Independent variable & Estimate & S.E. & $\boldsymbol{\beta}$ & \multicolumn{1}{c}{ C.R. } \\
\hline $\begin{array}{l}\text { Emotional Regulation } \\
\text { Strategies }\end{array}$ & $<---$ & Negative Affect & -.148 & .052 & -.13 & $-2.829^{* *}$ \\
Positive Affect & $<---$ & $\begin{array}{l}\text { Emotional Regulation } \\
\text { Ptrategies }\end{array}$ & .240 & .025 & .42 & $9.586^{* * *}$ \\
Positive Affect & $<---$ & Negative Affect & -.040 & .028 & -.06 & -1.468 \\
\hline
\end{tabular}

Note. ${ }^{* * *} \mathrm{p}<.001 ;{ }^{* *} \mathrm{p}<.01 ;{ }^{*} \mathrm{p}<.05$

As can be seen in Table 2, negative affect significantly and negatively predicts emotional regulation strategies $(\beta=-.13, \mathrm{p}<.01)$. Moreover, emotional regulation strategies were found to significantly and positively predict positive affect $(\beta=.42$, $\mathrm{p}<.001)$.

\subsection{Path Analysis Findings of the Final Model}

In Table 2, it is seen that some path coefficients are not statistically significant. Thus, the insignificant paths were excluded from the analysis. The analysis was repeated. The goodness of fit 
indices of the final full mediating model obtained as a result of the repetition of the analysis were found to be; $\chi^{2}(1, \mathrm{~N}=436)=2.15, \mathrm{p}>.05 ; \chi^{2} / \mathrm{sd}=2.15 ; \mathrm{GFI}=.99 ; \mathrm{CFI}=.99 ; \mathrm{NFI}=.98 ; \mathrm{AGFI}=.98$; RMSEA $=.05$ (90\% confidence interval for RMSEA $=.000-.149)$. In the interpretation of these goodness of fit indices, the fit criteria suggested by Schermelleh-Engel et al. (2003) were taken into account. The goodness of fit index values of the final full mediating model are shown in Table 3.

Table 3.

Goodness of Fit Indices of the Final Full Mediating Model

\begin{tabular}{lccc}
\hline Goodness of Fit Indices & Fit Criteria & Values of the Model & State of the Fit \\
$\mathrm{p}$ value & $.05<\mathrm{p} \leq 1.00$ & $\mathrm{p}=.14$ & Good fit \\
$\chi^{2} / \mathrm{sd}$ & $2 \leq \mathrm{X} 2 / \mathrm{sd} \leq 3$ & 2.15 & Acceptable fit \\
RMSEA & $0 \leq \mathrm{RMSEA} \leq .05$ & .05 & Good fit \\
GFI & $.95 \leq \mathrm{CFI} \leq 1.00$ & .99 & Good fit \\
$\mathrm{CFI}$ & $.97 \leq \mathrm{CFI} \leq 1.00$ & .99 & Good fit \\
NFI & $.95 \leq \mathrm{NFI} \leq 1.00$ & .98 & Good fit \\
AGFI & $.90 \leq \mathrm{AGFI} \leq 1.00$ & .98 & Good fit \\
\hline
\end{tabular}

Source: Schermelleh-Engel, Moosbrugger and Müller (2003).

As illustrated in Table 4, the final full mediating, it can be argued that the model has a good fit with the data. Furthermore, the standardized path coefficients of the final full mediating model obtained by repeating the analysis after the insignificant paths were excluded are shown in Figure 3. In addition, the path analysis results of the final full mediating model are given in Table 4 .

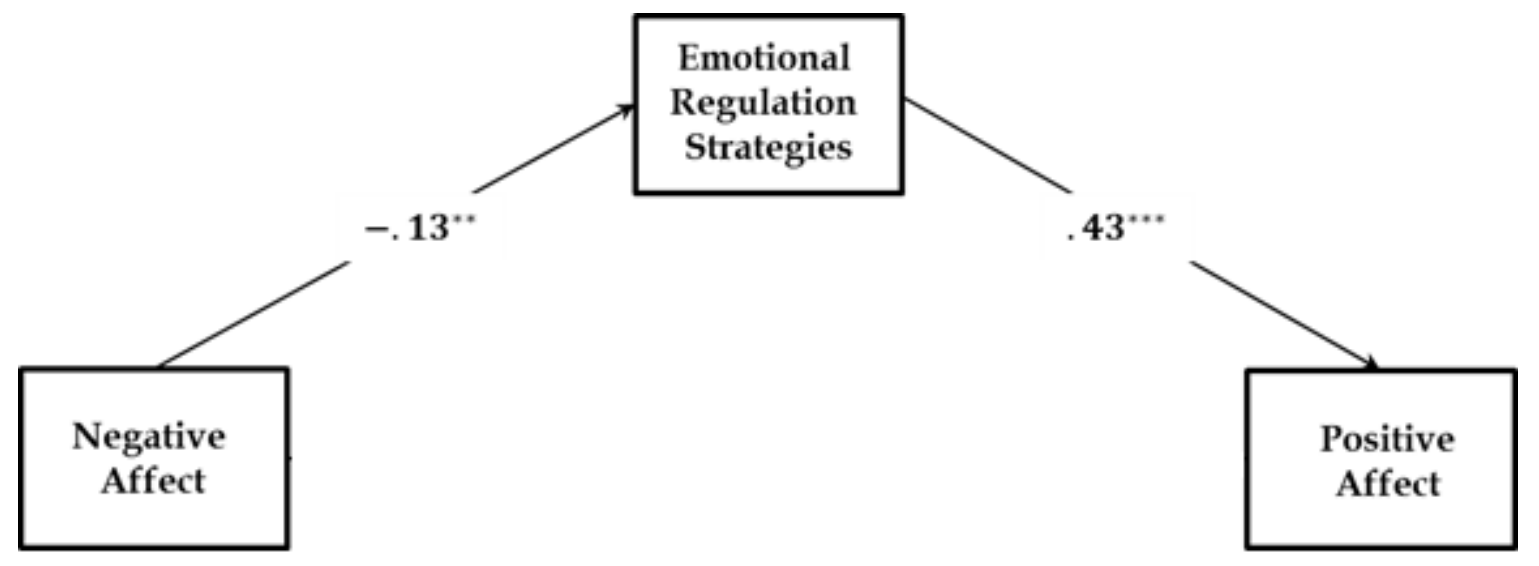

Figure 3. Standardized path coefficients of the final full mediating model $\left({ }^{* * *} \mathrm{p}<.001 ; * * \mathrm{p}<.01\right)$

In Figure 3, the standardized path coefficients of the final full mediating model are presented. Here, it is seen that one unit increase in negative affect decreases individuals' use of emotional regulation strategies by $0.13(t=-.2 .829 ; p<.01)$. On the other hand, one unit increase in emotional regulation strategies increases individuals' positive affect by $0.43(t=9.848 ; p<.001)$.

Table 4.

Path Analysis Results of the Final Full Mediating Model

\begin{tabular}{lllcccc}
\hline Dependent variable & & Independent variable & Estimate & S.E. & $\boldsymbol{\beta}$ & C.R. \\
\hline $\begin{array}{l}\text { Emotional Regulation } \\
\text { Strategies }\end{array}$ & $<---$ & Negative Affect & -.148 & .052 & -.13 & $-2.829^{* *}$ \\
Positive Affect & $<--$ & $\begin{array}{l}\text { Emotional Regulation } \\
\text { Strategies }\end{array}$ & .245 & .025 & .43 & $9.848^{* * *}$ \\
\hline
\end{tabular}

Note. ${ }^{* *} \mathrm{p}<.001 ;{ }^{* *} \mathrm{p}<.01$ 


\subsection{Mediation Test}

The mediator effect of emotional regulation strategies in the relationship between negative affect and positive affect was tested. To this end, the stages of testing mediation suggested by Baron and Kenny (1986) were taken into account. The direct effect of negative affect on positive affect was found to be significant $(\beta:-.12 ; t=-2.527)(p<.05)$. The mediator effect of the variable of emotional regulation strategies was added to this, it was observed that this effect decreased $(\beta:-.06 ; t=-1.468)$ and the $\mathrm{p}$ value became insignificant $(\mathrm{p}>.05)$. This finding proves that emotional regulation strategies are a full mediator in the relationship between negative affect and positive affect.

\subsection{Significance of Indirect Effects (Bootstrapping Analysis)}

The significance of the mediator effect of emotional regulation strategies was evaluated by using the bootstrapping analysis. The findings are presented in Table 5.

Table 5.

Bootstrapping Analysis Findings

\begin{tabular}{lllll}
$\begin{array}{l}\text { Independent } \\
\text { Variable }\end{array}$ & Mediator Variable & $\begin{array}{l}\text { Dependent } \\
\text { Variable }\end{array}$ & $\begin{array}{l}\text { Bootstrap } \\
\text { Coefficient } \\
(\beta)\end{array}$ & $\begin{array}{l}95 \% \text { Confidence } \\
\text { Interval (Lower- } \\
\text { Upper Limit) }\end{array}$ \\
\hline
\end{tabular}

Negative Affect --> Emotional Regulation Positive $\quad-.057^{*} \quad[-.105,-.011]$ Strategies Affect

Note: Bootstrap was conducted on 1000 samples (Hayes, 2017). $\beta=$ Standardized.* $p<.05$.

From the bootstrapping test findings in Table 5, the full mediator effect of emotional regulation strategies in the relationship between negative affect and positive affect was found to be significant $(b=-.057,95 \% \mathrm{GA}=-.105,-.011)$. Thus, the full mediator role of emotional regulation strategies in the relationship between negative affect and positive affect has been proven.

\section{Discussion and Conclusion}

The purpose of the current study is to determine the mediator role of emotional regulation strategies in the relationship between positive affect and negative affect experienced by individuals during the COVID-19 pandemic. According to the findings of the study, negative affect significantly and negatively predicts emotional regulation strategies of individuals. In addition, individuals' use of emotional regulation strategies predicts their positive affect significantly and positively. In addition, emotional regulation strategies were found to have a full mediator role in the relationship between negative affect and positive affect.

According to the first finding of the current study, negative affect significantly and negatively predicts emotional regulation strategies of individuals. As the relevant literature is reviewed, it is seen that there are studies that have reported findings similar to this finding of the current study (Brook et al., 2013; Casey et al., 2013; Chiu et al., 2020; Fredrickson et al., 2003; Garofalo et al., 2020; Tugade \& Fredrickson, 2004; Vanderlind et al., 2020; Vitale et al., 2018; Yoon \& Rottenberg, 2020; Quoidbach et al., 2010). The reason for this finding can be explained as follows: Negative emotional experiences can be an obstacle to the use of effective and adaptive emotional regulation strategies. One possible reason for this situation may be that individuals have difficulty accepting their negative emotions. It is known that individuals with low psychological flexibility tend to avoid such negative emotional experiences or use incompatible coping skills (Harris, 2019; Hayes et al., 2004). It is obvious that negative emotions do not provide pleasant experiences as positive emotions do. At this point, it can be said that people do not accept negative emotions and do not use emotional regulation strategies and use denial as a defence mechanism.

According to the second finding of the current study, individuals' use of emotional regulation strategies significantly and positively predicts their positive affect. This finding of the current 
study concurs with the existing research in the literature (Chiu et al., 2020; Ghorbani et al., 2020; Lindsey, 2020; Lopez \& Denny, 2019; Southward \& Cheavens, 2020; Vitale et al., 2018; Yosefi, 2015; Wante et. al., 2018). All these findings emphasize that individuals' use of effective and adaptive emotional regulation strategies may increase the probability of their experiencing positive emotions. This research finding can be evaluated as follows: The starting point of the concept of emotional regulation is the transformation of negative emotional experiences that may harm the person into a form that will facilitate the individual's adaptation to life and support his/her wellbeing. This can be achieved through the effective and adaptive use of emotional regulation strategies. It is known that individuals who do not have sufficient emotional regulation skills have more negative emotional experiences (Eisenberg et al., 1994). Since the needs for increasing pleasure and avoiding pain can be met with effective emotional regulation strategies (Koole, 2009), it can be thought that positive emotions arise along with pleasant experiences

According to the last finding of the current study, emotional regulation strategies have a full mediator role in the relationship between negative affect and positive affect. Parallel to studies in the literature (Barrett et al., 2001; Blalock et al., 2016; Karademas et al., 2011; Kobylińska et al., 2020; Nezlek \& Kuppens, 2008; Sutton et al., 2009; Talaei-Khoei et al., 2017; Tugade \& Fredrickson, 2007; Uhl et al., 2019; Verzeletti et al., 2016), the current study has proved the effect of emotional regulation strategies in replacing negative emotions with positive emotions. This research finding can be interpreted as follows: Emotional regulation is a process in which an individual tries to attain desired emotions. In this process, positive and negative emotions can be increased or decreased. At this point, it can be thought that emotion regulation strategies are an important step in turning negative emotions into positive emotions and making them beneficial for the individual. Thus, emotional regulation strategies can be considered as a promising and regulating factor for individuals.

Evaluating the findings in terms of education function in raising human as a social being; fulfilling this function in the education process is not possible only by gained the necessary knowledge and skills to the individuals. To achieve this, the individual must feel good and show his / her potential at the highest level. At this point, studies are needed to conduct to protect the individual's positive mental health. In accordance with this need, this study contributes individuals to produce less negative emotions and to experience a positive affect process by using more emotion regulation strategies. As a result, the findings and information of this study shows a positive effect especially on education function in raising human as a social being.

In the COVID-19 pandemic, which spreads and shows its effect in all over the world, the protection of mental health as well as physical health of individuals has great importance. At this point, maintaining a balance between positive and negative emotions experienced by individuals can be achieved through effective use of emotion regulation strategies. Research results, revealed that emotion regulation strategies have a full mediating role in the relationship between negative emotions and positive emotions. It is thought that the findings obtained as a result of the research can be a guide for mental health professionals and future research.

\subsection{Suggestions}

Many different strategies are used to protect and improve mental health by regulating positive and negative emotions. These strategies used can vary from culture to culture as well as from individual to individual. In some cultures, expression of some emotions is prohibited or condemned, which can cause individuals to suppress their positive emotions (Miyamoto \& Ma, 2011; Tugade \& Fredrickson, 2007). For this reason, intercultural studies on emotional regulation are also needed. Since most of the studies on this subject, including the present study, have been carried out with a cross-sectional method, it is thought that conducting longitudinal studies in which people are repeatedly examined in different time periods in the future may contribute to the literature. 


\section{References}

Affleck, G., \& Tennen, H. (1996). Construing benefits from adversity: Adaptotional significance and disposltional underpinnings. Journal of Personality, 64(4), 899-922. https://doi.org/10.1111/j.14676494.1996.tb00948.x

Aldao, A., Nolen-Hoeksema, S., \& Schweizer, S. (2010). Emotion-regulation strategies across psychopathology: A meta-analytic review. Clinical Psychology Review, 30(2), 217-237. https:// doi.org/10.1016/j.cpr.2009.11.004

Baron, R. M., \& Kenny, D. A. (1986). The moderator-mediator variable distinction in social psychological research: Conceptual, strategic, and statistical considerations. Journal of Personality and Social Psychology, 51(6), 1173-1182. https:// doi.org/0022-3514/86/S00.75

Barrett, L. F., Gross, J., Christensen, T. C., \& Benvenuto, M. (2001). Knowing what you're feeling and knowing what to do about it: Mapping the relation between emotion differentiation and emotion regulation. Cognition \& Emotion, 15(6), 713-724. https:// doi.org/10.1080/02699930143000239

Berenbaum, H., Raghavan, C., Le, H. N., Vernon, L. L., \& Gomez, J. J. (2003). A taxonomy of emotional $\begin{array}{lll}\text { disturbances. Clinical Psychology: Science and } & \text { 206-226. }\end{array}$ https://doi.org/10.1093/clipsy.bpg011

Blalock, D. V., Kashdan, T. B., \& Farmer, A. S. (2016). Trait and daily emotion regulation in social anxiety disorder. Cognitive Therapy and Research, 40(3), 416-425. https:/ / doi.org/10.1007/s10608-015-9739-8

Brook, M., Brieman, C. L., \& Kosson, D. S. (2013). Emotion processing in Psychopathy Checklist - Assessed psychopathy: A review of the literature. Clinical psychology review, 33(8), 979-995. https:// doi.org/10.1016/j.cpr.2013.07.008

Casey, H., Rogers, R. D., Burns, T., \& Yiend, J. (2013). Emotion regulation in psychopathy. Biological Psychology, 92(3), 541-548. https:// doi.org/10.1016/j.biopsycho.2012.06.011

Chiu, H. T., Yee, L. T. S., Kwan, J. L. Y., Cheung, R. Y. M., \& Hou, W. K. (2020). Interactive association between negative emotion regulation and savoring is linked to anxiety symptoms among college students. Journal of American College Health, 68(5), 494-501. https:// doi.org/10.1080/07448481.2019.1580712

Danziger, N., Faillenot, I., \& Peyron, R. (2009). Can we share a pain we never felt? Neural correlates of empathy in patients with congenital insensitivity to pain. Neuron, 61(2), 203-212. https://doi.org/10.1016/j.neuron.2008.11.023

Dong, L., \& Bouey, J. (2020). Public mental health crisis during COVID-19 pandemic, China. Emerging Infectious Diseases, 26(7), 1616-1618. https://doi.org/10.3201/eid2607.200407

Duy, B., \& Yildiz, M. A. (2014). Adaptation of the regulation of emotions questionnaire (REQ) for adolescents. Turkish Psychological Counseling and Guidance Journal, 5(41), 23-35.

Ehring, T., Tuschen-Caffier, B., Schnülle, J., Fischer, S., \& Gross, J. J. (2010). Emotion regulation and vulnerability to depression: spontaneous versus instructed use of emotion suppression and reappraisal. Emotion, 10(4), 563-572. https:// doi.org/10.1037/a0019010

Eisenberg, N., Fabes, R. A., Murphy, B., Karbon, M., Maszk, P., Smith, M., ... \& Suh, K. (1994). The relations of emotionality and regulation to dispositional and situational empathy-related responding. Journal Of Personality and Social Psychology, 66(4), 776.

Ekman, P., \& Friesen, W. V. (2003). Unmasking the face: A guide to recognizing emotions from facial expressions. Los Altos, CA: Malor Books.

Field, A. (2009). Discovering statistics using SPSS:(and sex and drugs and rock'n'roll). Sage.

Folkman, S., \& Moskowitz, J. T. (2000). Positive affect and the other side of coping. American Psychologist, 55(6), 647-654. https://doi.org/10.1037/0003-066X.55.6.647

Ford, B. Q., \& Gross, J. J. (2018). Emotion Regulation: Why Beliefs Matter. Canadian Psychology, 59(1), 1-14. https://doi.org/10.1037/cap0000142

Fraenkel J. R, \& Wallen, N. E. (1993). How to design and evaluate research in education (2nd ed.). Singopore: McGraw-Hill.

Fredrickson, B. L. (2001). The role of positive emotions in positive psycholgy: the broaden-and-build theory of positive emotions. American Psychologist, 56(3), 218-226. https:// doi.org/10.1037/0003-066X.56.3.218

Fredrickson, B., Tugade, M., Waugh, C., \& Larkin, G. (2003). What good are positive emotions in crises? A prospective study of resilience and emotions following the terrorist attacks on the united states on september 11th, 2001. Journal of Personality and Social Psychology,84(2), 365-376. https:// doi.org/10.1037/0022-3514.84.2.365

Frijda, N. H. (1986). The emotions. Cambridge, UK: Cambridge University Press. 
Garofalo, C., Neumann, C. S., Kosson, D. S., \& Velotti, P. (2020). Psychopathy and emotion dysregulation: More than meets the eye. Psychiatry Research, 290, 1-9. https://doi.org/10.1016/j.psychres.2020.113160

Gençöz, T. (2000). Positive and negative affect schedule: A study of validity and reliability. Turkish Journal of Psychology, 15(46), 19-28.

Ghorbani, S., Kameneh, A. S., Motahedy, A., \& Alipour, Z. (2020). Comparative effectiveness of cognitivebehavioral therapy and dialectical behavior therapy on emotion regulation, positive and negative affection, aggressive and self-harm behaviors of 13-16-year-old female students. International Journal of Multicultural and Multireligious Understanding, 7(9), 20-32. http://dx.doi.org/10.18415/ijmmu.v7i9.1883

Greenberq, L. S. (2002). Emotion-focused therapy: Coaching clients to work through their feelings. Washington, DC: American Psychological Association.

Gross, J. J. (1999). Emotion regulation: Past, present, future. Cognition EEmotion, 13(5), 551-573. https://doi.org/10.1080/026999399379186

Gross, J. J. (2013). Emotion regulation: taking stock and moving forward. Emotion (Washington, DC), 13(3), 359-365. https://doi.org/10.1037/a0032135

Gross, J. J., \& Jazaieri, H. (2014). Emotion, emotion regulation, and psychopathology: An affective science perspective. Clinical Psychological Science, 2(4), 387-401. https:/ / doi.org/10.1177\%2F2167702614536164

Gross, J. J., \& John, O. P. (2003). Individual differences in two emotion regulation processes: implications for affect, relationships, and well-being. Journal of Personality and Social Psychology, 85(2), 348-362. https://doi.org/10.1037/0022-3514.85.2.348

Gruber, J., Harvey, A. G., \& Gross, J. J. (2012). When trying is not enough: Emotion regulation and the effortsuccess gap in bipolar disorder. Emotion, 12(5), 997-1003. https://doi.org/10.1037/a0026822

Harris, J. (2019). ACT made simple: An easy-to-read primer on acceptance and commitment therapy. Canada: Raincoast Books.

Hayes, A. F. (2017). Introduction to mediation, moderation, and conditional process analysis: A regression-based approach. New York: Guilford.

Hayes, S. C., Wilson, K. G., Gifford, E. V., Bissett, R., Piasecki, M., Batten, S. V., ... \& Gregg, J. (2004). A preliminary trial of twelve-step facilitation and acceptance and commitment therapy with polysubstanceabusing methadone-maintained opiate addicts. Behavior Therapy, 35(4), 667-688. https://doi.org/10.1016/S0005-7894(04)80014-5

Heinzen, H., Koehler, D., Smeets, T., Hoffer, T., \& Huchzermeier, C. (2011). Emotion regulation in incarcerated young offenders with psychopathic traits. Journal of Forensic Psychiatry \& Psychology, 22(6), 809-833. https:/ / doi.org/10.1080/14789949.2011.623171

Kanade, T., Cohn, J. F., ve Tian, Y. (2000). Comprehensive database for facial expression analysis. In Proceedings Fourth IEEE International Conference on Automatic Face and Gesture Recognition (Cat. No. PR00580) (pp. 46-53). IEEE.

Karademas, E. C., Tsalikou, C., \& Tallarou, M. C. (2011). The impact of emotion regulation and illnessfocused coping strategies on the relation of illness-related negative emotions to subjective health. Journal of Health Psychology, 16(3), 510-519. https:/ / doi.org/10.1177\%2F1359105310392093

Kline, R. B. (2015). Principles and practice of structural equation modeling. New York: Guilford.

Kobylińska, D., Zajenkowski, M., Lewczuk, K., Jankowski, K. S., \& Marchlewska, M. (2020). The mediational role of emotion regulation in the relationship between personality and subjective well-being. Current Psychology, 1-14. https://doi.org/10.1007/s12144-020-00861-7

Koole, S. L. (2009). The psychology of emotion regulation: An integrative review. Cognition and Emotion, 23(1), 4-41. https:/ / doi.org/10.1080/02699930802619031

Koole, S. L., Van Dillen, L. F., \& Sheppes, G. (2011). The self-regulation of emotion. Guilford Press.

Kosson, D. S., McBride, C. K., Miller, S. A., Riser, N. R., \& Whitman, L. A. (2018). Attentional bias following frustration in youth with psychopathic traits: Emotional deficit versus negative preception. Journal of Experimental Psychopathology, 9(2), 1-21. https:/ / doi.org/10.5127\%2Fjep.060116

Le Doux, J. (1996). The emotional brain: The mysterious underpinnings of emotional life. New York: Simon and Schuster.

Le Doux, J. (2012). Rethinking the emotional brain. Neuron, 73(4), 653-676. https://doi.org/10.1016/j.neuron.2012.02.004

Lindsey, E. (2020). Relationship context and emotion regulation across the life span. Emotion, 20(1), 59-62. https://doi.org/10.1037/emo0000666 
Lopez, R. B., \& Denny, B. T. (2019). Negative affect mediates the relationship between use of emotion regulation strategies and general health in college-aged students. Personality and Individual Differences, 151, 1-7. https://doi.org/10.1016/j.paid.2019.109529

Major, B. C. (2013). The role of positive emotions in facilitating the regulation of emotion in response to negative stressors (Doctoral dissertation). Wake Forest University, North Carolina, USA.

McLean, C. P., \& Foa, E. B. (2017). Emotions and emotion regulation in posttraumatic stress disorder. Current Opinion in Psychology, 14, 72-77. https:// doi.org/10.1016/j.copsyc.2016.10.006

McRae, K., \& Gross, J. J. (2020). Emotion regulation. Emotion, 20(1), 1-9. https://doi.org/10.1037/emo0000703

Miyamoto, Y., \& Ma, X. (2011). Dampening or savoring positive emotions: a dialectical cultural script guides emotion regulation. Emotion, 11(6), 1346-1357. https://doi.org/10.1037/a0025135

Nezlek, J. B., \& Kuppens, P. (2008). Regulating positive and negative emotions in daily life. Journal of Personality, 76(3), 561-580. https:// doi.org/10.1111/j.1467-6494.2008.00496.x

Neuman, L. W. (2007). Toplumsal araştırma yöntemleri: nitel ve nicel yaklaşımlar. Özge, S. (Çev.), İstanbul: Yayın Odasi.

Pressman, S. D., \& Cohen, S. (2005). Does positive affect influence health?. Psychological Bulletin, 131(6), 925971. https:// doi.org/10.1037/0033-2909.131.6.925

Quoidbach, J., Berry, E. V., Hansenne, M., \& Mikolajczak, M. (2010). Positive emotion regulation and wellbeing: Comparing the impact of eight savoring and dampening strategies. Personality and Individual Differences, 49(5), 368-373. https:/ / doi.org/10.1016/j.paid.2010.03.048

Schermelleh-Engel, K., Moosbrugger, H., \& Müller, H. (2003). Evaluating the fit of structural equation models: Tests of significance and descriptive goodness-of fit measures. Methods of Psychological Research Online, 8(2), 23-74.

Sheppes, G., Suri, G., \& Gross, J. J. (2015). Emotion regulation and psychopathology. Annual Review of Clinical Psychology, 11, 379-405. https:/ / doi.org/10.1146/annurev-clinpsy-032814-112739

Shrout, P. E., \& Bolger, N. (2002). Mediation in experimental and nonexperimental studies: New procedures and recommendations. Psychological Methods, 7(4), 422- 445. https://doi.org/10.1037/1082-989X.7.4.422

Southward, M. W., \& Cheavens, J. S. (2020). More (of the right strategies) is better: disaggregating the naturalistic between-and within-person structure and effects of emotion regulation strategies. Cognition and Emotion, 1-8. https:/ / doi.org/10.1080/02699931.2020.1797637

Spindler, H., Denollet, J., Kruse, C., \& Pedersen, S. S. (2009). Positive affect and negative affect correlate differently with distress and health-related quality of life in patients with cardiac conditions: Validation of the Danish Global Mood Scale. Journal of Psychosomatic Research,67(1), 57-65. https://doi.org/10.1016/j.jpsychores.2008.11.003

Sutton, R. E., Mudrey-Camino, R., \& Knight, C. C. (2009). Teachers' emotion regulation and classroom management. Theory into Practice, 48(2), 130-137. https:// doi.org/10.1080/00405840902776418

Tabachnick, B.G., \& Fidell, L.S. (2019). Using multivariate statistics. (7th ed.). Pearson Education.

Talaei-Khoei, M., Nemati-Rezvani, H., Fischerauer, S. F., Ring, D., Chen, N., \& Vranceanu, A. M. (2017). Emotion regulation strategies mediate the associations of positive and negative affect to upper extremity physical function. Comprehensive Psychiatry, 75, 85-93. https:// doi.org/10.1016/j.comppsych.2017.03.005

Tugade, M. M., \& Fredrickson, B. L. (2004). Resilient individuals use positive emotions to bounce back from negative emotional experiences. Journal of Personality and Social Psychology,86(2), 320-333. https://doi.org/10.1037/0022-3514.86.2.320

Tugade, M. M., \& Fredrickson, B. L. (2007). Regulation of positive emotions: Emotion regulation strategies that promote resilience. Journal of Happiness Studies, 8(3), 311-333. https://doi.org/10.1007/s10902-0069015-4

Uhl, K., Halpern, L. F., Tam, C., Fox, J. K., \& Ryan, J. L. (2019). Relations of emotion regulation, negative and positive affect to anxiety and depression in middle childhood. Journal of Child and Family Studies, 28(11), 2988-2999. https:// doi.org/10.1007/s10826-019-01474-w

Van Bavel, J. J., Baicker, K., Boggio, P. S., Capraro, V., Cichocka, A., Cikara, M., ... \& Drury, J. (2020). Using social and behavioural science to support COVID-19 pandemic response. Nature Human Behaviour, 4, 460471. https:// doi.org/10.1038/s41562-020-0884-Z

Vanderlind, W. M., Millgram, Y., Baskin-Sommers, A. R., Clark, M. S., \& Joormann, J. (2020). Understanding positive emotion deficits in depression: From emotion preferences to emotion regulation. Clinical Psychology Review, 76,1-11. https://doi.org/10.1016/j.cpr.2020.101826 
Verzeletti, C., Zammuner, V. L., Galli, C., \& Agnoli, S. (2016). Emotion regulation strategies and psychosocial well-being in adolescence. Cogent Psychology, 3(1), 1-15. https://doi.org/10.1080/23311908.2016.1199294

Vitale, J., Kosson, D. S., Resch, Z., \& Newman, J. P. (2018). Speed-accuracy tradeoffs on an affective lexical decision task: Implications for the affect regulation theory of psychopathy. Journal of Psychopathology and Behavioral Assessment, 40(3), 412-418. https:/ / doi.org/10.1007/s10862-018-9652-z

Wante, L., Van Beveren, M. L., Theuwis, L., \& Braet, C. (2018). The effects of emotion regulation strategies on positive and negative affect in early adolescents. Cognition and Emotion, 32(5), 988-1002. https://doi.org/10.1080/02699931.2017.1374242

Watson, D., Clark, L. A., \& Carey, G. (1988). Positive and negative affectivity and their relation to anxiety and depressive disorders. Journal of Abnormal Psychology, 97(3), 346. https://doi.org/1988-35982-001

Wegner, D., Erber, R., \& Zanakos, S. (1993). Ironic processes in the mental control of mood and mood-related thought. Journal of Personality and Social Psychology, 65(6), 1093-1104. https://doi.org/10.1037/00223514.65.6.1093

World Health Organization [WHO]. (2020). UN Policy Brief on COVID-19 and the need for action on mental health. https://www.who.int/emergencies/diseases/novel-coronavirus-2019/events-as-they-happen

Yesilyaprak, B. (2000). Egitimde rehberlik hizmetleri [Counselling services in education]. Ankara: Nobel.

Yoon, S., \& Rottenberg, J. (2020). Why do people with depression use faulty emotion regulation strategies? Emotion Review, 12(2), 118-128. https:/ / doi.org/10.1177/1754073919890670

Yosefi, J. (2015). The relationship between emotional regulation and positive and negative emotion with psychological well-being of students. Journal of Neyshabur University of Medical Sciences, 3(1), 66-74.

Yurtsever, G. (2004). Emotional regulation strategies and negotiation. Psychological Reports, 95(3), 780-786. https://doi.org/10.2466/pr0.95.3.780-786 